\title{
Judiciarização do privado e violência contra a mulher
}

\author{
María del Carmen Cortizo \\ Universidade Federal de Santa Catarina (UFSC)
}

\author{
Priscila Larratea Goyeneche \\ Universidade Federal de Santa Catarina (UFSC)
}

\section{Judiciarização do privado e violência contra a mulher}

Resumo: Este trabalho apresenta alguns dos paradoxos presentes na Lei Maria da Penha, tendo como referentes teóricos as recentes análises sobre os processos de jurisdiciarização da vida privada. A mencionada Lei trata sobre relações que por muito tempo foram consideradas fora do espaço regulatório do Estado e tem por objetivo principal erradicar e punir as formas de violência doméstica contra a mulher. Os paradoxos, aos que fazemos referência, apresentam-se tanto no grau de ampliação dos processos de criminalização, quanto na aplicação concreta por parte do sistema jurídico-judicial do Estado. Neste sentido, assinalamos os problemas de uma aplicação da lei que possa vir a reproduzir a cultura jurídica conservadora presente na sociedade e, portanto, nos operadores de direitos, caso não se compreenda a questão da violência contra a mulher e as suas formas de prevenção e punição como uma questão cultural complexa, que não se esgota na jurisdiciarização do espaço privado.

Palavras-chave: Lei Maria da Penha, violência contra a mulher, jurisdiciarização, cultura jurídica.

\section{"Judicialization" of the Private and Violence against Women}

Abstract: This article presents some paradoxes present in the Maria da Penha Law, using as theoretical references the recent analyses about the processes of "judicialization" of private life. The law mentioned applies to relations that for many years were considered outside the regulatory space of the State. Its principal objective is to eradicate and punish domestic violence against women. The paradoxes to which we refer appear both in the degree of expansion of the processes of criminalization, as well as in the concrete application by the State's legal-judicial system. We indicate problems related to application of the law in a way that reproduces the conservative legal culture present in society and therefore, in the operators of rights. This is exacerbated if the question of violence against women, as well as forms for prevention and punishment, are not understood as a complex cultural issue that is not limited to the "judicialization" of private space.

Key words: Maria da Penha law, violence against women, "judicialization," legal culture. 


\section{Apresentação}

\section{Em briga de marido e mulher ninguém mete a colher!}

A naturalização da violência contra a mulher, em especial a doméstica, levou durante muito tempo à invisibilidade de tais atos, à não consideração dos mesmos como crimes e consequentemente à impunidade dos agressores.

$\mathrm{O}$ processo de ampliação da proteção social e de reconhecimento de direitos nesta área acontece a partir de uma nova concepção da vida social e, sobretudo, da vida privada e da família, trazendo para o espaço público relações outrora impenetráveis. A nova concepção da vida privada a que fazemos referência assenta no entendimento da categoria gênero como uma relação social ligada muito mais a fatores culturais que a elementos decorrentes das diferenças meramente biológicas.

Este processo não se deu sem que fortes lutas precisassem ser travadas. Foi, sobretudo, a partir da década de 1970 que o movimento feminista empunhou a bandeira pela visibilidade das agressões e pelo reconhecimento da violência contra a mulher como um grave problema social. Os movimentos sociais, em especial os feministas e de defesa dos direitos humanos, passam então a encabeçar esta tendência de progressiva ampliação da criminalização da violência de gênero, que se torna matéria de regulação jurídica e proteção estatal.

\section{A nova mulher na nova família}

Historicamente os sistemas de gênero designaram espaços e papéis distintos a homens e mulheres: aos homens o mundo produtivo e às mulheres $\mathrm{o}$ espaço reprodutivo. Porém, a inserção cada vez maior das mulheres no mundo do trabalho, os novos arranjos familiares, somado ao crescente número de mulheres que assumem papéis de liderança nos mais diversos campos, trazem profundas transformações nas relações de convívio e de organização social. Desta forma, como assinalam Carreira, Ajamil e Moreira, as reivindicações e conquistas feministas por igualdade

[...] transcendem o plano individual para incidir em toda a sociedade, trazendo consigo marcantes transformações pessoais e coletivas, que têm como consequência profundas mudanças na estrutura social, na organização familiar, nas formas de produção e consumo, no mundo do trabalho e das responsabilidades públicas (CARREIRA; AJAMIL; MOREIRA, 2001,p.9).
Tratar das relações de gênero é compreender que esta definição vai muito além daquela dada biologicamente, onde somos "machos" ou "fêmeas" de acordo com o sexo que nascemos. O gênero não é dado $a$ priori no ato do nascimento e sim construído socioculturalmente "através de uma educação diferenciada para homens e mulheres, induzindo e fortalecendo papéis e estereótipos" (LISBOA; PINHEIRO, 2005, p. 4). Desta maneira, os sujeitos são constituídos através de relações de gênero em homens ou mulheres, resultando então em masculino ou feminino.

É impossível falar de mulheres, ou de sistemas de gênero sem adentrarmos à temática das famílias, já que a história de uma questão vem quase sempre inserida no contexto da outra. No que diz respeito à violência doméstica contra as mulheres, trata-se de um fato presente no seio das relações familiares e afetivas, revelando-se o lado mais doloroso das mesmas.

A partir dos anos 1960, alguns avanços tecnológicos atingem de maneira significativa a instituição familiar e a vida das mulheres, assim a pílula anticoncepcional desvinculou o sexo da reprodução. Na década de 1980, outras descobertas trouxeram a reprodução in vitro. Ainda na década de 1980, no Brasil era promulgada a atual Constituição Federal, que trazia alterações referentes à família, entre elas a sociedade conjugal compartilhada, e a igualdade jurídica entre os filhos legítimos e ilegítimos. As mudanças não cessaram na década de 1990, com os estudos sobre o DNA, abre-se a possibilidade para que os homens sejam responsáveis por sua reprodução biológica. No Brasil, em 1993, o Estatuto da Criança e do Adolescente (ECA) intervêm mais uma vez na instituição familiar, dessacralizando a família ao expressar a necessidade de se proteger legalmente as crianças até da sua própria família, quando assim for necessário, ao tempo em que traz como direito básico da criança o convívio familiar.

A organização doméstica se transforma, as mulheres passam a trabalhar e a chefiar famílias. A escola, a televisão e os novos padrões de consumo passam a interferir intensamente nas relações familiares. A globalização e as políticas neoliberais tornam as pessoas menos protegidas, mais sujeitas à lógica do mercado, os serviços públicos, em boa parte, são substituídos por serviços do setor privado.

Conforme apontam Debert e Gregori,

No caso de agressões entre casais ou gerações na família, a questão é muito mais complicada, pois se combina com a hipocrisia da defesa da família. Não se trata da família patriarcal, nem da família como reino de proteção e afetividades, mas da família como única solução para o cidadão que falhou e que é pobre e incapaz de exercer os direitos conquistados (DEBERT, 2001 apud DEBERT; GREGORI, 2008,p. 175). 
Diversos autores (GOLDANI, 2002; MARTIN, 1995; PARELLA, 2001; CAMPOS; MIOTO, 2003) concordam que as atuais transformações no mundo do trabalho alteram a capacidade dos homens para atuarem como provedores, alterando de modo significativo a configuração da família, cabendo agora às mulheres parte substancial do elevado custo social. Ao tempo em que as mulheres veem seus papéis tradicionais alterados, os homens sofrem com a perda da capacidade de prover seus lares o que muitas vezes aumenta as chances de tornarem-se violentos.

As mulheres com suas múltiplas jornadas, não apenas dão conta dos cuidados domésticos, garantindo a reprodução de suas famílias, como também contribuem para o PIB nacional (são responsáveis em $40 \%$ pelo PIB mundial) e constituem $52 \%$ da população votante em nosso país ${ }^{1}$.

O problema da violência doméstica pode ser considerado como resultado de dois fatores prinicpais. Em primeiro lugar, a crise da família: no Brasil, a proteção social tem caráter fortemente clientelista e paternalista, que visa em grande parte o controle da população. Tais políticas mantiveram um cunho residual, atuando na falência dos canais naturais de proteção (família e mercado). Com a ascensão das doutrinas neoliberais o país iniciou um processo de reformas e desregulamentações que agravou ainda mais a situação da maioria da população desprotegida. Neste processo, as famílias foram mais uma vez requisitadas a dar conta da proteção de seus membros, sem receber o respaldo necessário, seja por parte do Estado, seja pelo mercado. Esta desproteção, sem dúvida, colabora na geração de conflitos conjugais, na medida em que os papéis de gênero tradicionais acabam sofrendo alterações - a capacidade do macho de prover o lar já não é mais a mesma. Em segundo lugar, o machismo, resultado de uma cultura fortemente paternalista e com fortes valores morais e religiosos.

\section{Maria, Maria ${ }^{2}$}

Hoje em dia, no Brasil, vivemos em uma democracia formal, porém como sinaliza Vieira (2007, p, 104) "Estados de direito democrático [...] estão instalados em sociedades muito pouco democráticas. [...] Edificam-se Estados de direito democrático em sociedades limitadas em suas manifestações e interesses, com forte presença autoritária, na prática política e na própria cultura". Temos um Estado de direito declarado, mas ainda não totalmente concretizado e é neste contexto que, em 2006, é promulgada a Lei Maria da Penha com a finalidade de ampliar a proteção das mulheres vítimas de violência.

A Lei de Combate à Violência Doméstica e Familiar contra a Mulher (Lei Maria da Penha), n. 11.340, de 07 de agosto de 2006 (BRASIL, 2006), responde em boa medida ao movimento internacional de ampliação da defesa dos direitos humanos que impulsiona transformações internas aos Estados. Como diz Almeida (2005, p. 13):

Constrói-se a representação de um mundo global, capaz de níveis crescentes de integração, que favorece a emergência de uma sociedade civil global, que participará da governança global, capaz de assegurar a defesa e a implementação dos direitos humanos - por que não? - em escala também global.

Como exemplo, é possível citar o impacto e a influência de documentos como a Declaração de Direitos Humanos de Viena (1922) que reconheceu que a violência contra as mulheres infringe os direitos humanos (em 1995, a Convenção de Belém do Pará ratificou esta posição, ao elaborar um estatuto interamericano que tipifica as violências de gênero), a Convenção sobre a Eliminação de Todas as Formas de Discriminação contra a Mulher (Cedaw), de 1979; a Declaração e o Programa de Ação da Conferência Mundial de Direitos Humanos de Viena, de 1993; o Plano de Ação da Conferência Mundial sobre População e Desenvolvimento do Cairo, de 1994; a Convenção Interamericana para Prevenir, Punir e Erradicar a Violência contra a Mulher, de 1994; e a Declaração e a Plataforma de Ação da IV Conferência Mundial sobre a Mulher de Pequim, de 1995. O Brasil é o décimo oitavo país da América Latina e Caribe a contar com uma lei específica que trata a violência contra a mulher.

Não existe dúvida de que a Lei Maria da Penha representa um marco na luta pelos direitos das mulheres. Significa uma vitória dos movimentos feministas, e mais um avanço no que tange ao reconhecimento legal da igualdade através de um tratamento específico em relação aos diferentes segmentos e situações sociais.

Nas duas últimas décadas, como consequência da IV Conferência Mundial das Mulheres, realizada em Beijing em 1995, junto à visibilidade e legitimidade que o movimento de mulheres tem alcançado, consagra-se o princípio do Gender mainstreaming (também conhecido como transversalidade de gênero), que, centrado no reconhecimento da diversidade de gênero, trouxe um novo olhar na elaboração de políticas públicas, significando a reconstrução de uma humanidade diversa e democrática. A consideração deste princípio permite, sobretudo, a incorporação da perspectiva de gênero nas instituições e em todas as áreas das políticas públicas. Ou seja, Gender mainstreaming "é (re)organização, melhoramento, desenvolvimento e avaliação de processos políticos, de forma que a perspectiva da igualdade de gênero seja incorporada em todas as políticas em todos seus níveis e estágios, pelos atores normalmente envolvi- 
dos em sua elaboração" (COUNCIL OF EUROPE, 2008, tradução livre).

Internacionalmente, a eliminação de todas as formas de discriminação é reconhecida como um dos entraves ao processo democrático e ao desenvolvimento social. De acordo com a Organização Mundial da Saúde (OMS), a violência contra a mulher tornou-se "uma epidemia, que produz agravos à saúde física, psíquica e sexual das mulheres e meninas, devendo ser enfrentada com políticas públicas e a punição dos agressores" (OMS, 2008). De modo mais amplo, Almeida (2005, p. 27) sinaliza que

No Brasil, temos a violência endêmica estrutural cotidiana, que não é errática, mas dirigida sistematicamente a frações de classe e a categorias exploradas, sendo, cada vez mais, enraizada na cultura política autoritária do país, fecundada pelo medo, banalizada e naturalizada em todos os níveis da sociedade. Neste sentido, a luta pela defesa dos direitos civis, embora indiscutivelmente insuficiente, é política e tem caráter emancipatório.

Neste contexto, a Lei Maria da Penha pode ser vista como resultado de demandas históricas dos movimentos de mulheres e feministas, potencializadas pela criação da Secretaria Especial de Políticas para as Mulheres da Presidência da República (SPM/PR), e pelo trabalho articulado com os poderes Executivo, Legislativo e Judiciário (CFEMEA, 2007). Como também, de diversos compromissos internacionais assumidos pelo governo brasileiro, dado que estes funcionaram como forma de pressão para a aprovação da mesma. Porém, cabe lembrar que a simples promulgação da Lei, apesar de uma grande conquista não é suficiente, Dallari (1976 apud VIEIRA, 2007, p. 31) salienta que

Quem tiver consciência jurídica não se satisfaz com fórmulas abstratas, que nunca passam de meras abstrações, mas só aceita como Direito autêntico aquele que tem expressão concreta na vida social. E percebe que as regras aparentemente jurídicas, mas desprovidas de qualquer eficácia, são inúteis e até mesmo prejudiciais, porque apresentam o $\mathrm{Di}$ reito como simples jogo de palavras.

Um dos entraves para a efetivação da Lei é a questão da interpretação e aplicação realizada pelo Judiciário. Neste sentido, e como exemplo paradigmático, podemos lembrar o caso do juiz que entre os meses de junho e julho de 2008, negou 60 pedidos de medidas preventivas amparadas na Lei Maria da Penha, alegando serem inconstitucionais. Segundo ele, violariam o $\operatorname{artigo~} 5^{\circ}$ da Constituição Federal que diz que todos são iguais perante a lei, sem distinção de qualquer natureza, sendo homens e mulheres iguais em direitos e obrigações. Em entrevista ao jornal Correio do Povo (ANIS, 2008, online), o juiz afirmou, ainda, que "a melhor forma de a mulher se proteger é não escolher homem bagaceiro e pudim de cachaça, pedindo separação ou divórcio, quando preciso, e não perpetuando uma situação insustentável."

Outro grande problema é que muitas vezes as mulheres mantêm a esperança de que o companheiro mude de comportamento e acabam acreditando quando ele promete que não vai mais agredi-la. Não é à toa que, em pesquisa realizada em uma Delegacia da Mulher de João Pessoa, na Paraíba, entre janeiro e abril de 1999, Rifiotis constatou que na maioria das vezes os registros de ocorrência nem sequer configuravam "ocorrências passíveis de serem investigadas, mas sim relatos de cenas de conflitos intraconjugais":

\begin{abstract}
A percepção da psicóloga entrevistada é de que as 'clientes' não procuravam a delegacia em busca de uma ação jurídica, mas, antes, buscavam a solução de conflitos fora do âmbito jurídico, o que expressam em pedidos tais como chamar o companheiro para 'dar uma prensa', 'dar um susto' etc., ou simplesmente para uma orientação - 'saber dos direitos' - sem que isto implicasse a sua utilização concreta. Trata-se de uma demanda extrajudicial em que se procede conforme uma etiqueta e regras talhadas na informalidade e no 'bom-senso', por vezes independentemente do caso ser de 'crime de ação pública’ (MUNIZ, 1996 apud RIFIOTIS, 2004, p. 110).
\end{abstract}

O que se observa aqui é que, no âmbito da Delegacia da Mulher, a polícia não pode ser considerada apenas um elo de transmissão entre os conflitos intrafamiliares e o campo jurídico, mas deve ser entendida como espaço institucional de mediação no interior de relações sociais privadas (RIFIOTIS, 2004).

Não basta a existência de leis para que sejam alterados os costumes e regras de convivência nas sociedades. Concordamos com Weber (1995a apud RIFIOTIS, 2008, p. 229) quando diz que "a forma de legitimidade mais importante na sociedade moderna é a crença na legalidade", mas a ordem respeitada unicamente pela racionalidade endereçada a fins é geralmente menos estável do que aquela baseada no costume. O que torna as medidas judiciarizantes ainda muito frágeis em termos de capacidade de mudança de comportamentos e costumes.

Dominguez Figueirido (2003, apud AZEVEDO; CUNHA; VASCONCELLOS, 2008, p. 5) faz uma análise do processo legislativo com base no reconhecimento da existência de uma série de interações que têm lugar entre elementos distintos e que dão lugar a vários níveis ou âmbitos de racionalidade. Assim, 
Entre os âmbitos de racionalidade legislativa estão a comunicativa ou linguística (capacidade do emissor da norma transmitir com fluidez a mensagem ao receptor); jurídico-formal (inserção harmoniosa da nova lei no sistema jurídico); ética (sustentabilidade ética dos valores orientadores das condutas prescritas e dos fins buscados pela lei); e pragmática ou teleológica (adequação da conduta dos destinatários ao prescrito na lei e capacidade de alcançar os fins sociais perseguidos).

A seguir abordaremos a questão das dificuldades de implementação da lei, partindo da premissa de que as leis são feitas por (e para) homens e mulheres, que nascem e são socializados dentro da cultura. Que cultura é esta? Existe um padrão que permita certa generalização no caso brasileiro? Sendo assim, como se dá o processo de judiciarização das relações privadas?

\section{A judiciarização do privado}

Sabemos que a violência de gênero (aqui englobando a violência doméstica contra a mulher) é parte das relações de poder desiguais estabelecidas ao longo dos séculos entre homens e mulheres. Historicamente, o espaço doméstico foi considerado o espaço da privacidade por excelência, em oposição às ruas, ao trabalho, à política etc. que se consideravam espaços públicos. Esta visão apoiava e reforçava a ideia de que o espaço privado não era de interesse geral e, portanto, não merecia ser discutido publicamente e tampouco constituía objeto de intervenção estatal.

Embora na prática não exista apenas um único padrão de família e de relações entre os sexos, no imaginário social ainda persiste o modelo europeu de família mononuclear burguesa, com fortes apelos moralizantes e papéis sociais claramente definidos.

Importante fator moralizante e definidor de papéis na sociedade que não pode ser esquecido é a religião. No universo cultural ocidental e cristão, todas as mulheres são descendentes de Eva - a pecadora -, porém se convertem em Maria - a abnegada. Hoje em dia nosso Deus é um homem e é assim nas grandes religiões monoteístas: cristianismo, judaísmo, islamismo, bem como em outras religiões politeístas onde os deuses homens ten- dem a ser maioria. A religião perpetua e reproduz papéis, justifica-os, explica-os e os legitima. Esta é uma fonte da opressão contra as mulheres. O fato é que esta raiz permanece oculta, sepultada, arraigada tão profundamente que resulta difícil trazê-la à tona.

As mulheres são ensinadas que suas vidas devem ser vidas de entrega, e ainda que são capazes de realizar-se nesta entrega, amando os maridos, filhos, pais, alunos, doentes, pobres etc. Sempre amando aos outros mais que a si mesmas. Assim como Maria, a felicidade estaria condicionada ao amor ao próximo.

Na contramão desta lógica cultural perversa, o movimento feminista luta pelo reconhecimento da violência de gênero em todos seus aspectos. Um desses aspectos é o que se refere a criação de mecanismos jurídicos para ampliar o acesso ao sistema judiciário de causas antes tratadas como da ordem privada. A judiciarização, como é chamado este movimento, consiste na utilização do poder de polícia do Estado para intervir nas relações de poder do espaço privado. Rifiotis (2008) salienta ainda que a judiciarização não deve ser considerada como um equivalente de acesso à justiça, democratização e cidadania, ainda que seja parte da dinâmica das sociedades democráticas. Em determinados contextos, este processo pode, inclusive, limitar ou ameaçar a cidadania e a democracia.

No caso específico da violência contra a mulher, Rifiotis (2004, p. 89) diz que,

A ‘judiciarização’ é apresentada como conjunto de práticas e valores, pressupostos em instituições como a Delegacia da $\mathrm{Mu}-$ lher, e que consiste fundamentalmente em interpretar a 'violência conjugal' a partir de um ponto de uma leitura criminalizante e estigmatizada contida na polaridade 'vítimaagressor', ou na figura jurídica do 'réu'. A leitura criminalizadora apresenta uma série de obstáculos para a compreensão e intervenção nos conflitos interpessoais.

$\mathrm{O}$ autor aponta ainda outros limites e perigos que esta passagem do mundo privado para o mundo jurídico pode trazer, caso alguns aspectos sejam desconsiderados. Primeiramente, o perigo da simplificação e, de certa forma, naturalização da palavra violência: 
Violência é uma palavra singular. Seu uso recorrente a tornou de tal modo familiar que parece desnecessário defini-la. Ela foi transformada numa espécie de significado vazio, um artefato sempre disponível para acolher novos significados e situações. O seu campo semântico tem uma regra de formação: a constante expansão. A aparente unidade deste termo resulta de uma generalização implícita dos diversos fenômenos que ela designa sempre de modo homogeneizador e negativo (RIFIOTIS, 1999 apud RIFIOTIS, 2008, p. 226).

Desta maneira, a violência contra a mulher pode acabar não sendo problematizada, caindo na armadilha da dualidade vítima versus agressor ao se condenar ambas as partes previamente, sem considerar a totalidade e a diversidade dos próprios fenômenos denunciados, esquecendo que se trata de relações sociais complexas. Segundo Rifiotis (2008), o processo penal "domestica" a conflitualidade, traduzindo-a em uma polaridade excludente, típica do princípio jurídico processual do contraditório, transformando em categorias jurídicas simples e opostas a complexidade das relações de gênero. Outra questão que não pode ser deixada de lado diz respeito à criminalização de problemas sociais, tais como a violência doméstica que entra em choque com os processos de mediação e com os trabalhos psicossociais com os agressores.

Segundo Rifiotis (2008, p. 229):

É possível identificar um quadro com duas frentes de leitura da 'violência de gênero', as quais não precisariam ser excludentes, mas que a Lei 11.340/06, sobretudo, se a prática jurídica tornar preponderante o caráter penal de ação pública incondicionada, pode separar radicalmente. De um lado teríamos uma tendência, digamos, relacional, voltada ao trabalho com os agressores, a mediação a busca de soluções extrajudiciais etc. De outro, uma ênfase na dimensão penal, da responsabilização legal.

Para algumas vertentes do movimento feminista, a mediação ao invés da equidade, igualdade e protagonismo dos sujeitos produziria a revitimização e reprivatização da violência de gênero (DIGNEFFE; PARENT, 1998 apud RIFIOTIS, 2008). Por outro lado, a intervenção penal do Estado priva a vítima de seu espaço e anula seu poder de decisão. O que chama atenção é que, independentemente da postura neste caso, a favor ou contra as medidas penalizantes, mais duras ou mais suaves, todos criticam a legislação penal, em especial a Lei de Execução Penal, no que tange a realidade de execução destas penas, as condições lastimáveis dos abrigos e dos presídios não contribuem para ressocializar os apenados. "Menos ainda para lhes conceder respeito, consideração e o reconhecimento da dignidade da pessoa humana pelo Estado, ente que detém a guarda e o dever proteger os delinquentes enquanto seus cidadãos, ainda que apenados" (AMORIM, 2007, p. 3).

Gregori (1992, p. 134) lança mão de uma análise que aqui nos parece pertinente, segundo a autora,

a construção de dualidades - como 'macho' culpado e mulher 'vítima' - para facilitar a denúncia e indignação, deixando de lado o fato de que os relacionamentos conjugais são de parceria e que a violência pode ser também uma forma de comunicação, ainda que perversa, entre parceiros

pode ser perigosa e ferir a individualidade dos sujeitos em questão. Assim, concordamos com Azevedo, Cunha e Vasconcellos (2008) quando dizem que o conflito de gênero que está por trás da violência doméstica não pode ser tratado pura e simplesmente como matéria criminal. A volta do rito ordinário do processo criminal para apuração dos casos de violência doméstica contra a mulher não leva em consideração a relação íntima existente entre a vítima e o acusado, não considera a pretensão da vítima nem mesmo seus sentimentos e necessidades.

Outro entrave para a efetivação dos direitos se encontra nas características próprias dos órgãos da administração de justiça. Como afirma Dias (2005, p.13):

O Poder Judiciário ainda é uma das instituições mais conservadoras e sempre manteve uma posição discriminatória quanto aos gêneros masculino e feminino. [...] Na Constituição Federal, a igualdade formal vem decantada enfaticamente em duas oportunidades $\left(\mathrm{CF}, 5^{\circ}\right.$, I, e 226, $\left.\S 5^{\circ}\right)$. Porém, a constitucionalização da igualdade não basta, por si só, para alcançar a absoluta equivalência social e jurídica de homens e mulheres. [...] Nos processos envolvendo relações familiares, é onde mais se vê que os avanços legislativos ocorridos nos últimos tempos não altera o discurso dos juízes.

Dessa maneira, apesar da existência de normas internacionais e locais específicos para coibir e prevenir a violência doméstica contra a mulher, essas, por si só, não garantem a sua efetivação. Temos casos onde, apesar das queixas, não são instaurados inquéritos policiais para verificar a denúncia, demonstrando o descaso e o descrédito dos policiais que lidam com esta demanda e as decisões judiciais preconceituosas e carregadas de subjetividade. Facio (1996 apud OLIVEIRA, 2002) lembra que para que a análise de gênero do fenômeno legal seja completa, é necessário tomar em conta o preceito contido na Cedaw, cuja noção de "lei discriminatória" não exige que esta formalmente o seja, mas que sua interpreta- 
ção resulte em discriminação. Uma legislação aparentemente neutra é suscetível não somente a interpretações e aplicações diversas, mas também será incorporada culturalmente pela população de acordo com os valores, costumes e preconceitos presentes na mesma (OLIVEIRA, 2002).

Estereótipos, preconceitos e discriminações fazem parte de nossa cultura e estão profundamente inculcados nos indivíduos. São, portanto, parte das concepções de mundo dos policiais e operadores do direito, marcando a sua prática profissional, fazendo com que sejam reprodutores desta cultura que naturaliza e banaliza condutas violentas e performances desiguais entre homens e mulheres.

Deste modo, a relação entre lei e justiça - dissolvida pelo paradigma do positivismo jurídico - reaparece novamente hoje em termos de problema: nem toda lei (norma jurídica válida) é uma lei justa, mas os administradores de justiça devem aplicá-la igualmente, bastando que seja uma aplicação imparcial e independente, como se isso fosse possível.

Não obstante, considerando que os administradores de justiça (conceito mais amplo que o de juízes já que designa todos aqueles sujeitos diretamente envolvidos nos processos de tipo jurisdicional) traduzem (aplicam) a formulação hipotética da lei (a norma jurídica) em fato concreto (a resolução jurisdicional do conflito), portanto, encontram-se em posição privilegiada para abrir a possibilidade de expansão de outros tipos de práxis jurídicas alternativas ao paradigma cultural dominante.

A superação da perspectiva apontada deve ser ao mesmo tempo a configuração de um novo tipo de cultura jurídica. Para essa nova conformação, é necessária uma transformação intelectual e moral dos administradores de justiça dentro de um processo mais amplo (extenso, duradouro) - seguindo Gramsci de "reforma intelectual e moral" da sociedade, entendida como um todo, gerada a partir dos elementos progressistas presentes nessa mesma cultura jurídica, considerando as suas possibilidades de articulação em um projeto de construção de uma nova hegemonia radicalmente democrática.

\section{Considerações finais}

Faltam ainda políticas públicas e instituições do Estado que garantam a efetividade e a eficácia da Lei Maria da Penha. Embora não dependa de regulamentação, na prática, a efetivação da Lei tem se dado de maneira lenta e desigual. Em algumas localidades faltam casas-abrigo, centros de orientação e atendimento às vítimas, e centros de recuperação dos agressores, e mais, muitas vezes, as mulheres agredidas são orientadas, dentro da própria Delegacia, a não prestarem queixa contra seus agressores.
Além disso, falta a expansão de uma nova cultura democrática com novos valores. Vivemos em um tempo de relações sociais perversas, é preciso quebrar com este ciclo paternalista e machista que $a$ priori já violenta as mulheres aprisionando-as em papéis imaginários. É preciso libertar nossos homens, também, igualmente vítimas deste sistema que não os permite chorar, nem tampouco sofrer.

Somente com a passagem do tempo poderemos fazer uma análise mais detalhada da eficácia da Lei Maria da Penha na prevenção e repressão da violência doméstica contra a mulher. Porém o que já se pode dizer é que é extremamente punitiva, introduzindo novos tipos penais ${ }^{3}$ e expandindo o direito penal, impondo medidas privativas de liberdade que possivelmente não serão eficazes do ponto de vista psicossocial e sociocultural.

Este trabalho pretende trazer para a reflexão alguns dos paradoxos presentes na Lei Maria da Penha, que são os paradoxos da nossa cultura jurídica e em particular da cultura jurídica da administração da justiça contemporânea.

\section{Referências}

ALMEIDA, S. S. de. A política de direitos humanos no Brasil: paradoxos e dilemas para o Serviço Social. Revista Praia Vermelha, Rio de Janeiro, n. 13, p. 12-43, 2005.

AMORIM, M. S. Acesso à justiça e administração judicial da violência contra a mulher brasileira: políticas de despenalização e de penalização. In: XIII CONGRESSO DA ANPEDI, 2007. Anais... Disponível em: <http://conpedi.org/ manau s////arquivos / anais / campos / maria_stella_de_amorim.pdf $>$.Acesso em: 10 ago. 2009.

ANIS. Informe 07.08.2008.Disponível em: <http:// w w w . a n i s.org.br/informe/visualizar_informes.cfm?IdInformes=102>.Acesso em: 13. Ago. 2008.

AZEVEDO, R. G. de; VASCONCELLOS, F. B.; CUNHA, E. P. Juizados Especiais de Violência Doméstica e Familiar contra a Mulher. In: IX CONGRESO NACIONAL DE SOCIOLOGÍA JURÍDICA, 2008. Publicación de las Ponencias del Congreso. Rosario, Argentina: UNR, 2008.

BRASIL. Presidência da República. Lei n. 11.340, de 07 de agosto de 2006, Lei Maria da Penha. Disponível em: <http://www.planalto.gov.br/ccivil/_Ato2004-2006/2006/ Lei/L11340.htm>. Acesso em: 14 abr. 2008.

CAMPOS, M.; MIOTO, R. C. T. Política de assistência social e a posição da família na política social brasileira. Ser Social: Revista do Programa de Pós-Graduação em Política Social, UnB, Brasília, n. 12, p. 165-190, jan./jun. 2003. 
CARREIRA, D.; AJAMIL, M.; MOREIRA, T. Mudando o mundo: a liderança feminina no século 21. São Paulo: Cortez; Rede Mulher de Educação, 2001.

CFEMEA - CENTRO FEMINISTA DE ESTUDOS E ASSESSORIA. Lei Maria da Penha: do papel para a vida. Brasília, DF, 2007.

COUNCIL OF EUROPE. Human Rights and Legal Affairs: Gender Mainstreaming. Disponível em: <http:// www.coe.int/T/E/Human_Rights>.Acesso em: 17 ago. 2008.

DIAS, M. B. Manual de direito das famílias. Porto Alegre: Livraria do Advogado, 2005.

GOLDANI, A. M. Família, gênero e políticas: famílias brasileiras nos anos 90 e seus desafios como fator de proteção. Revista Brasileira de Estudos de População, v. 19, n. 1, jan./jun. 2002.

GREGORI, M. F. Cenas e queixas: um estudo sobre mulheres, relações violentas e a prática feminista. São Paulo: Paz e Terra, 1992.

.; DEBERT, G. G. Violência e gênero: novas propostas, velhos dilemas. Revista Brasileira de Ciências Sociais, v. 23, p. 165-185, 2008.

LISBOA, T. K.; PINHEIRO, E. A. A intervenção do Serviço Social junto à questão da violência contra a mulher. Revista Katálysis, Florianópolis, v. 8, n. 2, p. 199-210, jul./dez. 2005.

MARTIN, C. Os limites da protecção da família. Revista Crítica de Ciências Sociais, Coimbra, Portugal, n. 42, p. 53-76, 1995.

OLIVEIRA, R. M. R. de. Para uma crítica da razão androcêntrica: gênero, homoerotismo e exclusão da ciência jurídica. Cadernos Themis Gênero e Direito, Porto Alegre, ano III, n. 3, p. 101-134, 2002.

OMS - Organização Mundial da Saúde. Estúdio multipaís de la OMS sobre salud de la mujer y violencia doméstica contra la mujer. Departamento Género y Salud de la Mujer. Ginebra. 2003 Disponível em: < http://www.who.int/gender/ violence/who_multicountry_study/summary_report/ chapter1/es/index1.html >. Acesso em: 17 ago. 2008.

PARELLA, S. Las políticas familiares. In: ADELANTADO, J. Câmbios en el Estado del Bienestar: Políticas sociales y desigualdades en España. Barcelona: Icaria, 2001.

RIFIOTIS, T. As delegacias especiais de proteção à mulher no Brasil e a "judiciarização" dos conflitos conjugais. Revista Sociedade e Estado, v. 19, n. 1, p. 85-119, jan./jul. 2004.
Judiciarização das relações sociais e estratégias de reconhecimento: repensando a 'violência conjugal' e a 'violência intrafamiliar'. Revista Katálysis, Florianópolis, v. 11, n. 2, p. 225-236, 2008.

SILVA SÁNCHEZ, J.-M. A expansão do Direito Penal aspectos da política criminal nas sociedades pósindustriais. Tradução de Luiz Otávio de Oliveira Rocha. São Paulo: Ed. Revista dos Tribunais, 2002.

VIEIRA, E. Os direitos e a política social. São Paulo: Cortez, 2007.

\section{Notas}

1 Atualmente dos mais de 130 milhões de eleitores inscritos na Justiça Eleitoral brasileira, as mulheres representam $51,7 \%$.

2 Trecho da música "Maria, Maria" de Milton Nascimento e Fernando Brant ("Mas é preciso ter força. É preciso ter raça. É preciso ter gana sempre. Quem traz no corpo a marca. Maria, Maria. Mistura a dor e a alegria”).

3 Sobre a expansão do direito penal ver SILVA SÁNCHEZ (2002).

\section{María del Carmen Cortizo}

maria.ufsc@gmail.com

Doutorado em Ciências Sociais pela Universidade Estadual de Campinas (Unicamp) Professora do Departamento de Serviço Social da Universidade Federal de Santa Catarina e do Programa de PósGraduação em Serviço Social da UFSC

\section{Priscila Larratea Goyeneche}

niniaprilg@gmail.com

Mestranda do Programa de Pós-Graduação em Serviço Social da UFSC

\section{UFSC - Programa de Pós-Graduação em Servi- ço Social \\ Centro Sócio-Econômico \\ Campus Universitário - Trindade \\ Florianópolis - Santa Catarina \\ CEP: 88010-970}

